\title{
Parametric optimization of powder mixed electrical discharge machining for nickel- based superalloy inconel-800 using response surface methodology
}

\author{
Satish Kumar ${ }^{1 *}$, Ashwani Kumar Dhingra ${ }^{1}$ and Sanjeev Kumar ${ }^{2}$
}

\begin{abstract}
Background: Electrical Discharge Machining (EDM) is a well-established non-conventional machining process for the machining of electrically conductive and difficult-to-machine materials. But its applications are limited because of the slow machining rate and poor surface finish. Powder mixed EDM (PMEDM) is unitary of the recent progresses in the EDM process in which powder particles mixed in the dielectric fluid results in higher machining rate and better surface quality. In the past, limited work has been found on PMEDM of Inconel-800 material. Researchers have reported about machining with different powder particles like aluminum powder, silicon carbide, graphite etc. in the dielectric fluid of EDM, but the effect of powder particles, i.e. Tungsten carbide, cobalt and boron carbide along with tool material i.e. copper, copper-chromium and graphite on Inconel-800 material has not been explored. The purpose of the present work is to look into the issue of tool material (Cu, copper-chromium, and graphite) along with powder particles (tungsten carbide, cobalt and boron carbide) suspended in EDM oil on Inconel-800 material.

Methods: The present work includes optimization of Material Removal Rate (MRR) and Tool Wear Rate (TWR) for the machining of Inconel-800 material using Powder Mixed Elctric Discharge Machining (PMEDM). Different input parameters such as peak current, pulse on-time, pulse off-time, tool and powder materials along with effect of three micro powder particles, i.e. tungsten carbide, cobalt and boron carbide and three electrodes i.e. copper, copper-chromium, and graphite have been considered for the experimentation. The box-Behnken method of Response Surface Methodology (RSM) has been used for designing the experiments along with the Desirability Approach for multiple response parameters optimization. The adequacy of the proposed mathematical models have also been tested using analysis of variance (ANOVA). Microstructure analysis and transfer of different factors on the machined surface has also been investigated using Scanning Electron Microscope (SEM), Energy Dispersive Spectrometer (EDS) and X - Ray Diffraction (XRD).

Results: The results showed that peak current, pulse on-time, and tool material significantly affects the Material Removal Rate (MRR) while peak current, pulse on-time, tool material and powder materials affected the Tool Wear Rate (TWR). Pulse off-time has a trifling effect on both MRR and TWR, while powder particles on MRR. From desirability approach, the optimal combination of parameters found to be current $1 \mathrm{amp}$, pulse on-time $0.98 \mu \mathrm{s}$, pulse off-time $0.03 \mu \mathrm{s}$, tool material 0.31 and the powder (suspended particles) 0.64 .
\end{abstract}

Conclusion: The analysis of the experimental observations highlights that the current, pulse on-time and tool material have found to be the most decisive factors for MRR, while current, pulse on-time, tool material and powder particles for TWR.

Keywords: Material removal rate, Tool wear rate, Desirability approach, Scanning electron microscope

\footnotetext{
* Correspondence: itsarungarg@gmail.com

'Department of Mechanical Engineering, University Institute of Engineering \&

Technology, Maharshi Dayanand University, Rohtak 124001, Haryana, India

Full list of author information is available at the end of the article
} 


\section{Background}

Inconel-800 i.e. iron-nickel-chromium based superalloy has numerous properties including excellent resistance to chloride stress-corrosion cracking, high strength and cryogenic properties. These attributes cause them an appealing option for the application in the aerospace industry, heat exchanger, and furnace components, and so on. Machining of the Inconel-800 is very difficult using conventional methods of machining because of these characteristics and the machining can be easily done by using different non-conventional/traditional machining techniques. Electrical Discharge Machining (EDM) is unitary of the non-traditional machining processes and can be well used for the machining of complex geometrical form (Kumar et al. 2010a, 2010b). Due to sudden cooling of molten metal in the EDM process, re-solidification takes place which brought on a recast layer on the machined surface (Zhang et al. 1997). The layer formed on the machined surface contains microcracks which slow down the wear and corrosion resistance of the EDM surface (Ekmekci and Erden 2004). With the advancement of EDM, the powders (suspended particles) mixed dielectric fluid has been used for enhancing the machining rate and tool wear rate (Klocke et al. 2004; Abbas et al. 2007; Kumar et al. 2009). Kumar et al. (2015a, b) evaluated the surface characteristics of the tool electrodes using powder mixed electrical discharge machining (PMEDM) process through Taguchi design. They have reasoned out that the tool material has the maximum effect on the surface roughness of electrode. Rajesh and Anand (2012) used multiple regressions and genetic algorithm model for choosing the optimal machining parameters in EDM process and resolved that the current is a vital parameter that affects the response parameters. Prabhu and Vinayagam (2012) examined the open features of D2 tool steel by combining multi-wall carbon nanotube in the dielectric fluid of EDM and obtained improvement in the surface finish by an norm of $34 \%$. Wu et al. (2009) researched the effect of surfactant on the features of the EDM process by taking peak current, open voltage, gap voltage and pulse duration as the input parameters. It has been found that the increased conductivity of dielectric improves the material removal rate. Kumar et al. (2012) evaluated the machining effectiveness with PMEDM on Inconel- 718 and examined the effect of input variables, i.e. polarity, tool material, peak current, duty cycle, gap voltage, and powder particles on machining efficiency. Experimental results showed that mixing of powder particles of graphite in the dielectric fluid improves the TWR and wear ratio. Kumar et al.(2010a, 2010b) used EN-24 tool steel, as a workable material with a copper electrode for experimentation with the abrasive mixed EDM process by suspending silicon powder $(2 \mathrm{~g} / \mathrm{l})$ in the kerosene dielectric fluid. Improved MRR and surface roughness (SR) have been achieved by mixing the fine particles of silicon in a dielectric fluid. Singh and Yeh (2012) applied the grey relational analysis for evaluating the response parameters, i.e. TWR, SR, and MRR by mixing abrasive powder particles in the dielectric fluid of EDM. They described that the powder mixed dielectric improved the response characteristics. Talla et al. (2015) used aluminum powder in kerosene oil as a dielectric medium in the EDM operation for the machining of aluminium-based metal matrix composite (MMC) which significantly improved the productivity as well as surface quality. Tzeng and Lee (2001) studied the result of silicon carbide, chromium, and copper powder as additives in the dielectric fluid on SKD 11 steel which significantly affects the EDM process performance. It was also found that the increase MRR can be accomplished by using smaller grain size of chromium particles as an additive. Jeswani (1981) researched the effect of powder particles of graphite in dielectric kerosene oil of EDM. He described that the concentration of graphite powder in kerosene oil improved the machining stability with increased MRR and reduced in TWR. Singh and Maheshweri (2006a, 2016b) investigated the innovative materials using fine powder particles of silicon carbide in the dielectric fluid with the achievement of better machining rates as compared to simple EDM. Kung et al. (2009) reported that machining performance can be improved by using aluminum powder as an additive in the dielectric fluid of EDM for the machining of cobalt-bonded tungsten carbide. Singh and Sharma (2016) optimized the multiperformance characteristics (MPCs), i.e. microhardness and surface roughness by using the PMEDM of the tungsten carbide alloy. Experimental results indicated that the mixing of powder particles of graphite in the dielectric fluid improves the open characteristics of tungsten carbide alloy. Toshimitsu et al. (2016) proposed a new EDM surface finishing method by using a chromium powder mixed fluid which formed chromium containing layer on the EDM finished surface. The chromium powder concentration is high on the EDM finished surface when the discharge current is low. Khazraji et al. (2016) studied the effect of process parameters by using abrasive powder particles of silicon carbide in the dielectric fluid of EDM. Talla et al. (2016) investigated the influence of various powderssuspended dielectrics and machining parameters on various EDM characteristics of Inconel 625. Results indicated that powder properties like thermal conductivity, electrical conductivity, stiffness and density play a critical part in changing the machining operation and the character of the machined surface. Long et al. (2016) used titanium powder in the dielectric fluid of EDM for the machining of SKD61, SKD11, and SKT4 die steels. Taguchi methods and analysis of variance were employed to identify the main parameters that affect the MRR. The answers indicated that electrode 

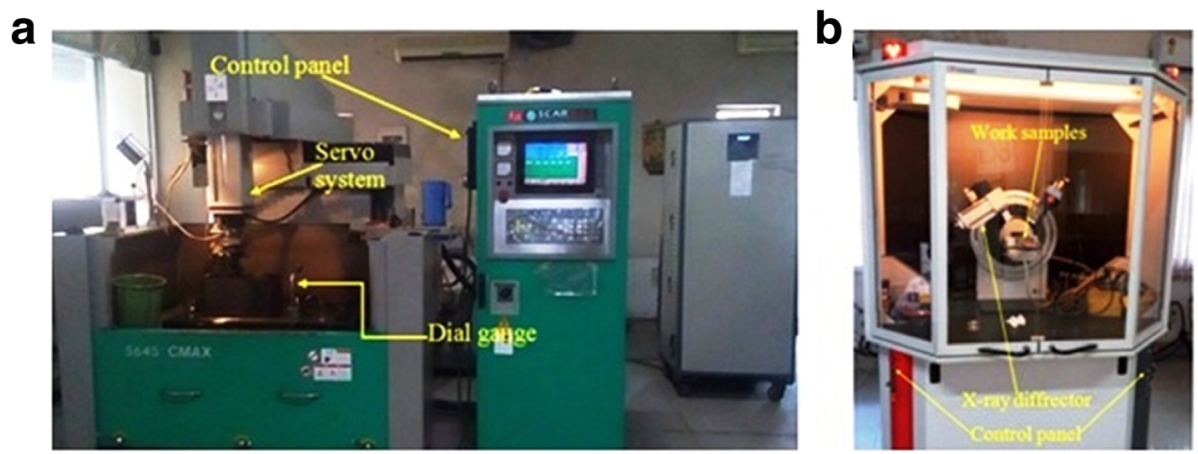

Fig. 1 a Schematic diagram and experimental setup for EDM machine of Inconel- 800; (b) X-ray diffraction machine

material, electric current, and powder concentration were the most significant parameters those influenced the MRR.

From the literature review, it has been found that insufficient work has been done on PMEDM of Inconel-800. The previous research work reported the machinability of titanium, die steel, composite matrix element, etc. merely a very limited work has been reported on Inconel-800 material. It can be also found that although several subjects have reported about machining with powder particle like aluminum powder, silicon carbide, graphite etc. in the dielectric fluid of EDM, but the effect of powder particles, i.e. Tungsten carbide, cobalt and boron carbide along with tool material i.e. copper, copper-chromium and graphite on Inconel-800 material has not been reported. The purpose of this work is to look into the issue of tool material ( $\mathrm{Cu}$, copper-chromium, and graphite) along with powder particles (tungsten carbide, cobalt and boron carbide) suspended in EDM oil on Inconel-800 material.

\section{Methods}

The experiments have been performed on the die sinking EDM machine (Model OSCARMAX S 645) at Central Institute of Hand Tools, Jalandhar-Punjab-INDIA. Figure 1(a) and (b) shows the EDM machine and schematic diagram of X-ray diffraction machine. Tungsten carbide, Cobalt and Boron carbide in the sort of micro powder particles with size 10-25 $\mu \mathrm{m}$ were mixed with EDM oil as per RSM design methodology for investigating the effects on MRR and TWR. On the ground of a literature survey, the pilot experiments have been done with the addition of tungsten carbide, cobalt and boron carbide powder ranging from 1 to $15 \mathrm{~g} / \mathrm{l}$ into the dielectric fluid to study the effect on MRR and TWR. From the results, it has been observed that at a powder concentration of $6 \mathrm{~g} / \mathrm{l}$, better MRR and TWR have been accomplished (Kolli and Kumar 2015; Toshimitsu et al 2016; Kansal et al 2005).

Table 1 Chemical composition of inconel-800

\begin{tabular}{lllllllll}
\hline Element & $\mathrm{Ni}$ & $\mathrm{Fe}$ & $\mathrm{Cr}$ & $\mathrm{C}$ & $\mathrm{MO}$ & $\mathrm{S}$ & $\mathrm{Si}$ & $\mathrm{Cu}$ \\
\hline$\%$ & Base material & 39.5 & 20.5 & $<0.1$ & 1.11 & $<0.015$ & $<1$ & $<0.75$ \\
\hline
\end{tabular}

Hence, for further experimentation, powder concentration has been taken as $6 \mathrm{~g} / \mathrm{l}$. A separate tank has been set up for mixing powder particles with the dielectric fluid. Copper and Copper-chromium have high melting point, high thermal and electrical conductivity, low cost and easy availability (Kumar et al. 2015a, 2015b). Khazraji et al. (2016) reported that graphite is also most widely applied because of its wide industrial applications. Therefore, Copper, Copper-chromium, and Graphite were selected as tool electrodes. The weight before and after the machining of each specimen has been measured using the high precise weighing machine. The density of Inconel- 800 is 7.94 $\mathrm{g} / \mathrm{cm}^{3}$. Among the three tool electrodes, the percentage of chromium in the copper-chromium tool is 1.36 . The compositions of work material and their mechanical properties are given in Tables 1 and 2. Each hole has machined to a deepness of 0.5 millimeter. MRR and TWR have been calculated after every experiment. Five process parameters, i.e. current $(\mathrm{Ip})$, pulse on-time $\left(\mathrm{T}_{\mathrm{on}}\right)$, pulse off-time $\left(\mathrm{T}_{\mathrm{off}}\right)$, powder (suspended particles) and tool material affecting MRR and TWR were identified using pilot study and reported results in the literature. Other experimental conditions along with their descriptions are presented in Table 3. Table 4 shows the input factors and their levels. Machined workpieces have also been analyzed using SEM, EDS and XRD techniques.

\section{Response surface methodology (RSM)}

Response Surface Methodology (RSM) is an assemblage of statistical and mathematical techniques applied for modeling and analysis of different problems. RSM is an efficient tool for developing, amending, and optimizing

Table 2 Mechanical properties of inconel-800

\begin{tabular}{ll}
\hline Density & $7.94 \mathrm{~g} / \mathrm{cm} 3$ \\
\hline Melting point & $1385 \mathrm{O}^{\mathrm{C}}$ \\
Tensile strength & $520 \mathrm{MPa}$ \\
Yield strength & $205 \mathrm{Mpa}$ \\
Elongation & $30 \%$ \\
\hline
\end{tabular}


Table 3 Experimental conditions

\begin{tabular}{ll}
\hline Working condition & Description \\
\hline Work piece & Inconel-800 $(150 \mathrm{~mm} \times 15 \mathrm{~mm} \times 6 \mathrm{~mm})$ \\
Tool material & $\begin{array}{l}\text { Copper, Copper-chromium and Graphite, } \\
\varnothing 12 \mathrm{~mm} \text { and length } 40 \mathrm{~mm} \\
\text { EDM Oil grade SAE } 450+W C \text {, Cobalt and } \\
\text { Dielectric }\end{array}$ \\
B $C$ P Powder \\
Flushing & Side flushing with pressure $0.5 \mathrm{Mpa}$ \\
Powder (suspended & $10-25 \mu \mathrm{m}$ \\
particles) size & \\
Polarity & Positive \\
Machining hole & $0.5 \mathrm{~mm}$ \\
\hline
\end{tabular}

the processes by combining several input variables and evaluate how their complex interactions affect the execution of the response variables (Natarajan et al. 2011; Lin et al. 2012). RSM analyze the experimental data by plotting residual plots for accuracy, contour plots and response curves (Vikram and Pradhan 2014). Box-Behnken design as a type of response does not contain fractional factorial design to determine the best response conditions (Khazraji et al. 2016). In RSM, Box-Behnken method has less number of trials hence less complicated in comparison to other methods (Sushil et al. 2016). Therefore, a Box-Behnken method of RSM was applied for analyzing the results. The relationship between output parameters and independent input variables is represented as follows:

$$
\mathrm{Y}=\mathrm{f}(\mathrm{A}, \mathrm{B}, \mathrm{C}, \mathrm{D} \text { and } \mathrm{E})
$$

Where $\mathrm{Y}$ is the output parameter and $\mathrm{f}$ is the output function, $A$ is peak current, $B$ is pulse on-time, $C$ is pulse off-time, $\mathrm{D}$ is tool material and $\mathrm{E}$ is a powder (suspended particles). For the purpose of analysis, the approximation of $\mathrm{Y}$ has been proposed using the fitted second-order polynomial regression model or quadratic model (Kung et al. 2009; Vikram and Pradhan 2014; Muthukumar et al. 2014; Sushil et al. 2016).

$$
Y=\sigma_{0}+\sum_{i=1}^{R} \sigma_{i} y_{i}+\sum_{i=1}^{R} \sigma_{i i} y_{i}^{2}+\sum_{i<j} \sigma_{i j} y_{i} y_{j}
$$

Where $\mathrm{Y}$ is the dependent output parameter and the $y_{i}$ $(1,2 \ldots \mathrm{R})$ are the independent of $\mathrm{R}$ quantitative input variables, $\sigma_{0}$ is constant and $\sigma_{i}, \sigma_{i i}, \sigma_{i j}$ are the coefficients of linear, quadratic, and mixing product terms. A model has been developed for 95\% confidence level.

\section{Results and discussions \\ Analysis of material removal rate (MRR)}

Based on planned model, the effect of process parameters on the MRR has been determined by using Design expert 6.0, software and corresponding data have been given in Table 5. Quadratic model results for MRR (before elimination) in the form of ANOVA are also given in Table 6. The value of R-Squared and Adjusted R-Squared is over 98.27\% and $96.89 \%$. This means proposed model provides the best relationship between input process parameters and response (MRR). The associated p-value for the present model is less than $5 \%(<0.05)$ i.e. $95 \%$ confidence level that means the model is significant (Montgomery et al. 2003). From the table, it can be observed that lack-of-fit is not significant as it is preferred. The terms $A, B, B^{2}, D^{2}, E^{2}$, and $A B$ are the significant terms, i.e. Peak current, pulse on-time, second order terms, pulse on-time, tool material, powder particles and interaction effects of peak current with pulse on-time has a significant effect. This result is in good agreement as reported by Mohanty et al. 2014 and Kumar et al. 2015a, 2015b. The other terms in the model are notsignificant.

The backward elimination procedure is applied to get rid of the non-significant terms so that the quadratic model to be fit. Table 7 demonstrates the reduced model for MRR. After backward elimination, the results indicate that the model is validated having R-Squared and Adjusted R-Squared as 97.22\% and $96.71 \%$, respectively. It is clear from one-factor plot that, MRR increased with the increase in current and pulse on-time while decreased when graphite is utilized as a tool material which can likewise be seen from Fig. 2(a, b and d). Pulse off-time and powder (suspended particles) have a real little bit effect on MRR as shown in Fig. 2(c) and (e). Figure 2(f) shows the contour plot for MRR. Figure 3(a) demonstrates the normal probability plot of the residuals for MRR and it can be understood that the residuals lie on a straight line which indicates the normal allocation of means errors. Each value has been compared with the predicted values, i.e.

\begin{tabular}{|c|c|c|c|c|c|c|}
\hline \multirow[t]{2}{*}{ S.No } & \multirow[t]{2}{*}{ Symbols } & \multirow[t]{2}{*}{ Input factors } & \multicolumn{3}{|l|}{ Level } & \multirow[t]{2}{*}{ Units } \\
\hline & & & -1 & 0 & 1 & \\
\hline 1 & A & Current (lp) & 4 & 8 & 12 & Ampere \\
\hline 2 & B & Pulse on-time $\left(\mathrm{T}_{\mathrm{on}}\right)$ & 60 & 90 & 120 & $\mu s$ \\
\hline 3 & C & Pulse off-time ( $\left.T_{\text {off }}\right)$ & 30 & 45 & 60 & $\mu s$ \\
\hline 4 & $\mathrm{D}$ & Tool material & Copper & Copper- Chromium & Graphite & - \\
\hline 5 & $E$ & Powder (Suspended particles) & Tungsten -carbide & Cobalt & Boron-Carbide & - \\
\hline
\end{tabular}

Table 4 Input factors and their levels 
Table 5 Design of experiments and results

\begin{tabular}{|c|c|c|c|c|c|c|c|}
\hline Run No. & Current (Amp) & $T_{\text {on }}(\mu s)$ & $T_{\text {off }}(\mu s)$ & Tool Material & Powder & MRR (mm3/min) & TWR $(\mathrm{mm} 3 / \mathrm{min})$ \\
\hline 1 & -1 & 0 & 1 & 0 & 0 & 4.353 & 0.007 \\
\hline 2 & 0 & 0 & 0 & 0 & 0 & 17.442 & 0.133 \\
\hline 3 & 0 & 0 & 1 & 1 & 0 & 13.95 & 1.957 \\
\hline 4 & 0 & 0 & 0 & -1 & -1 & 17.877 & 0.17 \\
\hline 5 & 0 & 0 & -1 & 0 & 1 & 17.494 & 0.143 \\
\hline 6 & 0 & 1 & -1 & 0 & 0 & 20.849 & 0.144 \\
\hline 7 & 0 & 0 & 1 & 0 & 1 & 15.97 & 0.042 \\
\hline 8 & 0 & 0 & 1 & -1 & 0 & 15.305 & 0.052 \\
\hline 9 & -1 & 0 & 0 & -1 & 0 & 4.552 & 0.022 \\
\hline 10 & 0 & 0 & 0 & 0 & 0 & 15.442 & 0.102 \\
\hline 11 & 0 & 0 & 0 & 0 & 0 & 16.442 & 0.102 \\
\hline 12 & 0 & 0 & 0 & 1 & -1 & 15.297 & 1.5 \\
\hline 13 & 0 & 0 & -1 & 1 & 0 & 15.636 & 1.774 \\
\hline 14 & 1 & 0 & -1 & 0 & 0 & 27.601 & 0.242 \\
\hline 15 & 0 & 0 & -1 & -1 & 0 & 15.187 & 0.095 \\
\hline 16 & 1 & 0 & 0 & 0 & 1 & 27.766 & 0.308 \\
\hline 17 & 1 & 0 & 1 & 0 & 0 & 27.87 & 0.018 \\
\hline 18 & 0 & 1 & 0 & 0 & -1 & 22.5 & 0.031 \\
\hline 19 & -1 & 0 & 0 & 1 & 0 & 4.803 & 1.524 \\
\hline 20 & 1 & 0 & 0 & 1 & 0 & 26.327 & 1.902 \\
\hline 21 & 0 & 1 & 1 & 0 & 0 & 16.398 & 0.015 \\
\hline 22 & -1 & 0 & 0 & 0 & 1 & 4.812 & 0.003 \\
\hline 23 & 0 & 0 & 0 & 1 & 1 & 16.403 & 1.697 \\
\hline 24 & 0 & 1 & 0 & -1 & 0 & 17.513 & 0.075 \\
\hline 25 & 1 & -1 & 0 & 0 & 0 & 19.423 & 0.182 \\
\hline 26 & 0 & 0 & 0 & 0 & 0 & 17.454 & 0.102 \\
\hline 27 & 0 & 0 & 1 & 0 & -1 & 17.052 & 0.002 \\
\hline 28 & -1 & 0 & -1 & 0 & 0 & 4.905 & 0.006 \\
\hline 29 & 1 & 0 & 0 & -1 & 0 & 27.649 & 0.2 \\
\hline 30 & -1 & 1 & 0 & 0 & 0 & 5.001 & 0.005 \\
\hline 31 & 0 & -1 & -1 & 0 & 0 & 12.398 & 0.015 \\
\hline 32 & 1 & 0 & 0 & 0 & -1 & 31.352 & 0.182 \\
\hline 33 & 0 & 0 & 0 & -1 & 1 & 18.121 & 0.2 \\
\hline 34 & 0 & 0 & 0 & 0 & 0 & 17.442 & 0.103 \\
\hline 35 & 0 & -1 & 0 & 0 & -1 & 13.293 & 0.024 \\
\hline 36 & 1 & 1 & 0 & 0 & 0 & 35.788 & 0.277 \\
\hline 37 & 0 & 1 & 0 & 1 & 0 & 15.074 & 1.785 \\
\hline 38 & 0 & 1 & 0 & 0 & 1 & 24.426 & 0.186 \\
\hline 39 & 0 & 0 & 0 & 0 & 0 & 17.442 & 0.013 \\
\hline 40 & 0 & 0 & -1 & 0 & -1 & 16.772 & 0.046 \\
\hline 41 & 0 & -1 & 1 & 0 & 0 & 12.196 & 0.015 \\
\hline 42 & -1 & -1 & 0 & 0 & 0 & 4.033 & 0.006 \\
\hline 43 & 0 & -1 & 0 & 0 & 1 & 11.569 & 0.109 \\
\hline 44 & 0 & -1 & 0 & 1 & 0 & 10.302 & 1.554 \\
\hline 45 & 0 & -1 & 0 & -1 & 0 & 11.07 & 0.242 \\
\hline 46 & -1 & 0 & 0 & 0 & -1 & 6.514 & 0.009 \\
\hline
\end{tabular}


Table 6 Analysis of variance for MRR (before elimination)

\begin{tabular}{|c|c|c|c|c|c|c|}
\hline Source & Sum of squares & DF & Mean squares & F - value & Prob $>F$ & \\
\hline Model & 2520.93 & 20 & 126.05 & 71.03 & $<0.0001$ & Significant \\
\hline A & 2134.51 & 1 & 2134.51 & 1202.89 & $<0.0001$ & \\
\hline B & 250.15 & 1 & 250.15 & 140.97 & $<0.0001$ & \\
\hline$C$ & 3.75 & 1 & 3.75 & 2.11 & 0.1584 & \\
\hline $\mathrm{D}$ & 5.62 & 1 & 5.62 & 3.17 & 0.0873 & \\
\hline E & 1.05 & 1 & 1.05 & 0.59 & 0.4493 & \\
\hline$A^{2}$ & $4.26 \times 10^{-03}$ & 1 & $4.26 \times 10^{-03}$ & $2.40 \times 10^{-03}$ & 0.9613 & \\
\hline$B^{2}$ & 7.58 & 1 & 7.58 & 4.27 & 0.0493 & \\
\hline$C^{2}$ & 4.99 & 1 & 4.99 & 2.81 & 0.1059 & \\
\hline$D^{2}$ & 19.52 & 1 & 19.52 & 11 & 0.0028 & \\
\hline$E^{2}$ & 12.23 & 1 & 12.23 & 6.89 & 0.0146 & \\
\hline$A B$ & 59.27 & 1 & 59.27 & 33.4 & $<0.0001$ & \\
\hline$A C$ & 0.17 & 1 & 0.17 & 0.095 & 0.7605 & \\
\hline$A D$ & 0.62 & 1 & 0.62 & 0.35 & 0.5602 & \\
\hline $\mathrm{AE}$ & 0.89 & 1 & 0.89 & 0.5 & 0.486 & \\
\hline$B C$ & 4.51 & 1 & 4.51 & 2.54 & 0.1233 & \\
\hline $\mathrm{BD}$ & 0.7 & 1 & 0.7 & 0.39 & 0.5362 & \\
\hline $\mathrm{BE}$ & 3.33 & 1 & 3.33 & 1.88 & 0.1829 & \\
\hline$C D$ & 0.81 & 1 & 0.81 & 0.46 & 0.5045 & \\
\hline CE & 0.81 & 1 & 0.81 & 0.46 & 0.5045 & \\
\hline $\mathrm{DE}$ & 0.19 & 1 & 0.19 & 0.1 & 0.749 & \\
\hline Residual & 44.36 & 25 & 1.77 & & & \\
\hline Lack of Fit & 40.85 & 20 & 2.04 & 2.91 & 0.1199 & Not significant \\
\hline Pure Error & 3.51 & 5 & 0.7 & & & \\
\hline Cor Total & 2565.29 & 45 & & & & \\
\hline \multicolumn{5}{|l|}{ Std. Dev. $=1.33$} & \multicolumn{2}{|c|}{ R-Squared $=0.9827$} \\
\hline \multicolumn{5}{|l|}{ Mean $=16.24$} & \multicolumn{2}{|c|}{ Pred R-Squared $=0.9343$} \\
\hline \multicolumn{5}{|l|}{ C.V. $=8.2$} & \multicolumn{2}{|c|}{ Adeq Precision = 35.184} \\
\hline \multicolumn{5}{|l|}{ PRESS $=168.46$} & \multicolumn{2}{|c|}{ Adj R-Squared = 0.9689} \\
\hline
\end{tabular}

Table 7 Analysis of variance for MRR (after backward elimination)

\begin{tabular}{llllll}
\hline Source & Sum of Squares & DF & Mean Square & F - Value & Prob $>$ F \\
\hline Model & 2494.05 & 7 & 356.29 & 190.05 & $<0.0001$ \\
A & 2134.51 & 1 & 2134.51 & 1138.55 & $<0.0001$ \\
B & 250.15 & 1 & 250.15 & 133.43 & $<0.0001$ \\
D & 5.62 & 1 & 5.62 & 3 & 0.0915 \\
E & 1.05 & 1 & 1.05 & 0.56 & 0.4591 \\
$D^{2}$ & 14.54 & 1 & 14.54 & 7.75 & 0.0083 \\
E $^{2}$ & 22.51 & 1 & 22.51 & 12.01 & 0.0013 \\
AB & 59.27 & 1 & 59.27 & 31.61 & $<0.0001$ \\
Residual & 71.24 & 38 & 1.87 & & 0.1165 \\
Lack of Fit & 67.73 & 33 & 2.05 & 2.92 & Not significant \\
Pure Error & 3.51 & 5 & 0.7 & & R-Squared $=0.9722$ \\
Cor. Total & 2565.29 & 45 & & & Adj R-Squared $=0.9671$ \\
Std. Dev. $=1.37$ & & & & & Pred R-Squared $=0.9599$ \\
Mean $=16.24$ & & & & & Adeq Precision $=57.25$ \\
C.V. $=8.43$ & & & & & \\
PRESS $=102.79$ & & & & & \\
\hline
\end{tabular}




\section{a}

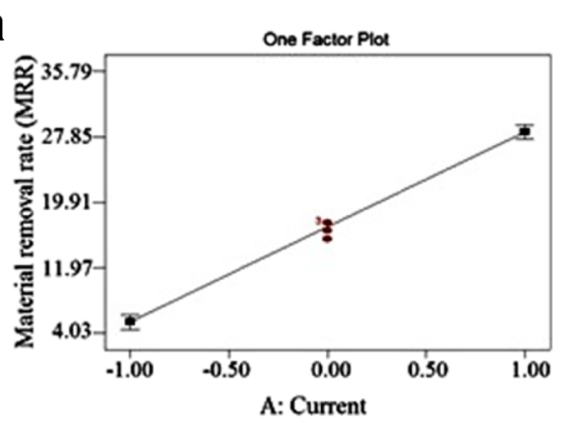

C

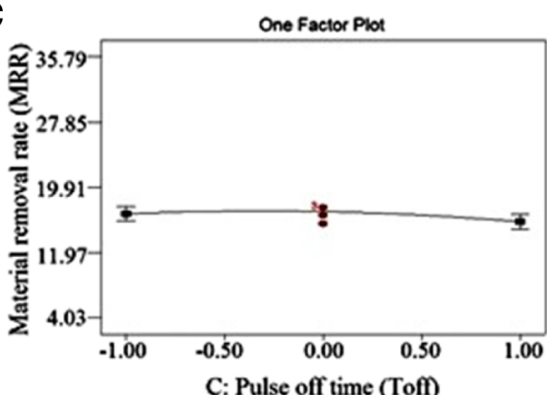

e

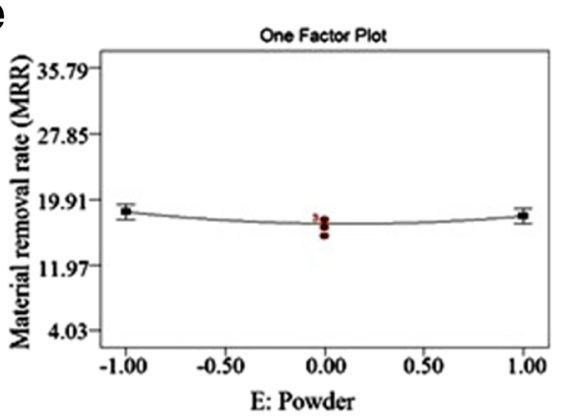

b

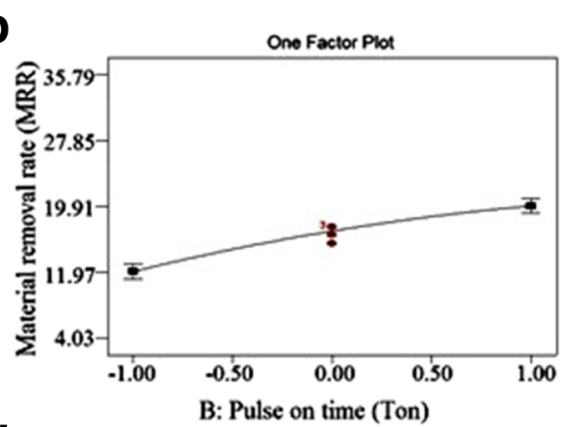

d

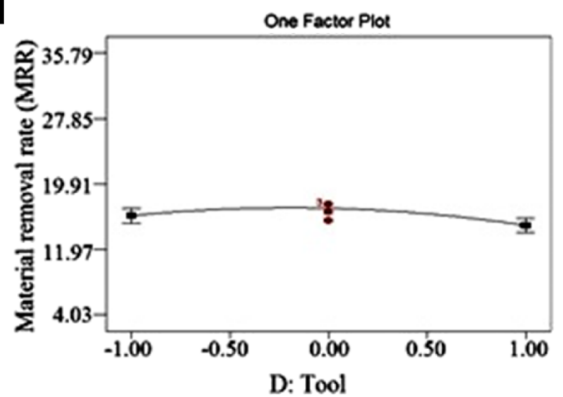

$\mathbf{f}$

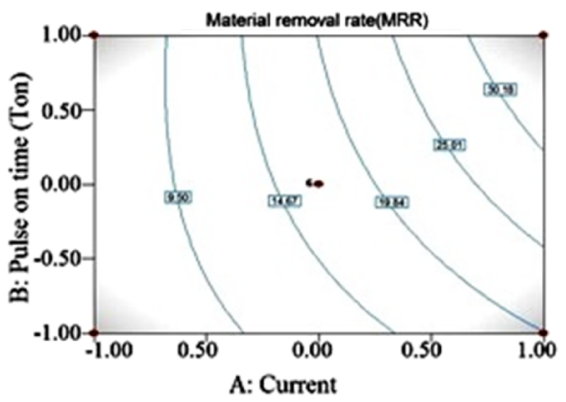

Fig. 2 a, b, c, d and e One factor plots for MRR; (f) Contour plot for MRR

calculated from the model as shown in Fig. 3(b). After the removal of not- the significant terms the final equation for MRR can be obtained as:

The equation for MRR in coded form:

$$
\begin{aligned}
\text { Material removal rate }(\mathrm{MRR})= & +16.14+11.55 \times \mathrm{A}+3.95 \\
& \times \mathrm{B}-0.59 \times \mathrm{D}-0.26 \times \mathrm{E}-1.19 \\
& \times \mathrm{D}^{2}+1.49 \times \mathrm{E}^{2}+3.85 \\
& \times \mathrm{A} \times \mathrm{B} .
\end{aligned}
$$

The equation for MRR in the actual form:

$$
\begin{aligned}
\text { Material removal rate }(\mathrm{MRR})= & 16.139+11.550 \times \text { Current } \\
& +3.954 \times \text { Pulse on-time }(\text { Ton }) \\
& -0.592 \times \text { Tool }-0.256 \\
\times & \text { Powder }-1.193 \times \text { Tool }^{2}+1.485 \\
\times & \text { Powder }{ }^{2}+3.84 \times \text { Current } \\
& \times \text { Pulse on-time }(\text { Ton }) .
\end{aligned}
$$

Figure 3(c, d, e, and f) show 3D surface plots for MRR. The MRR considerably increases with the increased peak current and pulse on-time. Therefore, maximum MRR can be achieved at peak current (12 A) and pulse on-time (120 $\mu \mathrm{s})$. This effect is due to dominant control over the input energy (Kansal et al. 2005). From the Fig. 3(e), it is clear that powder added in the dielectric have a trifling effect on the MRR. Also, tungsten carbide has the maximum effect on the MRR among the three powder particles.

\section{Analysis of Tool Wear Rate (TWR)}

Table 8 shows the ANOVA analysis (before elimination) for the TWR. The proposed model provides the best correlation between process parameters and response (TWR) as the values of R-Squared and Adjusted R-Squared are 99.15\% and $98.48 \%$ respectively. The p-value for the model is less than 0.05 indicates that the model is valid at $5 \%$ level of significance. The lack-of-fit is not significant as it is preferred. The terms A, C, D, E, $\mathrm{D}^{2}, \mathrm{BD}$ are significant model terms, i.e. peak current, pulse off-time, tool material, powder particles, second order terms of tool material and interaction effects of pulse on-time with the tool material have 

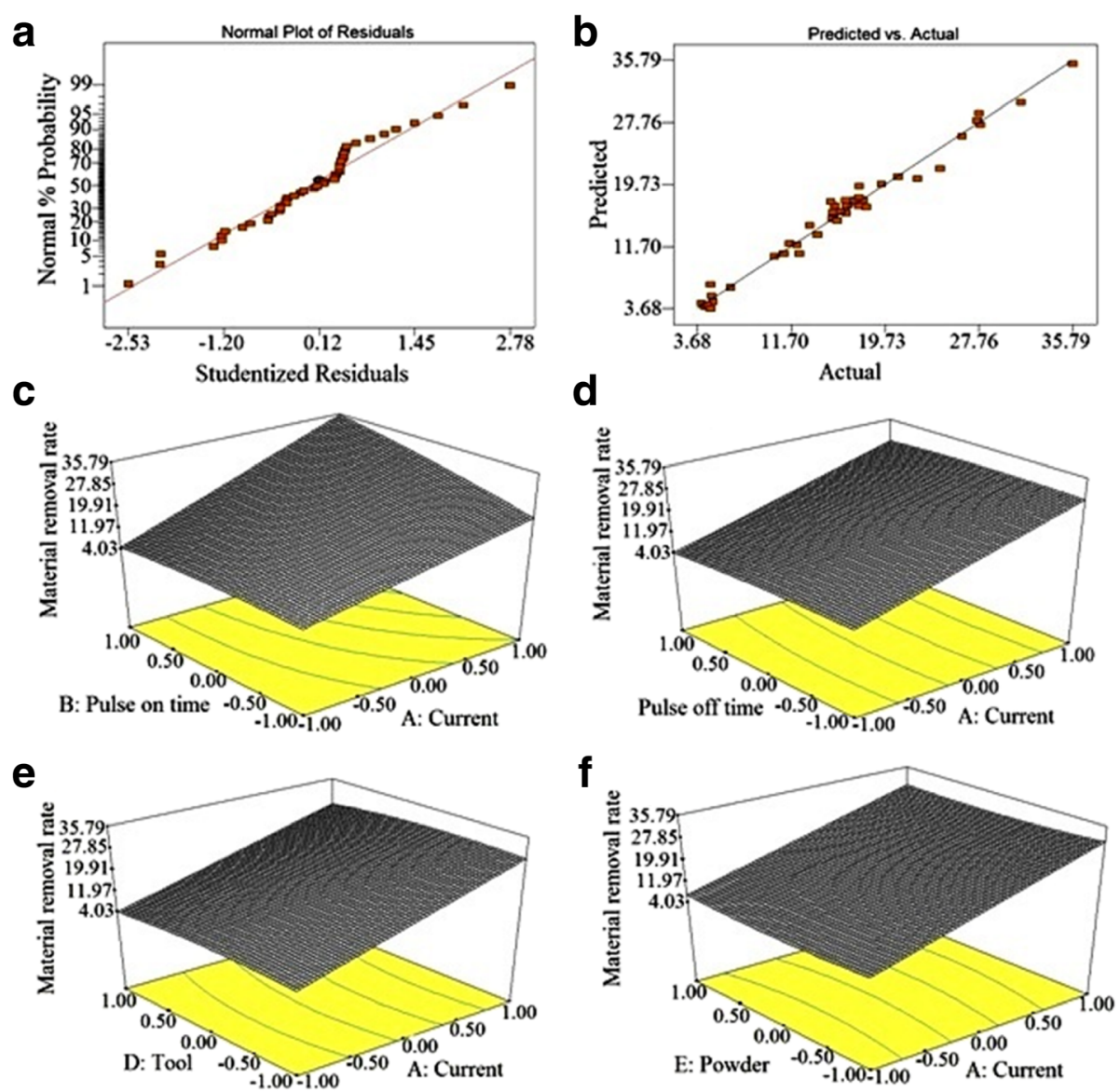

Fig. 3 Response surface plots: (a) normal probability residual plot, (b) Predicted v/s actual plot for MRR; $\mathbf{c}$, d, e, and $\mathbf{f} 3 D$ surface plot for MRR

a significant effect. The "Pred R-Squared" of 0.9673 is reasonable conformity with the "Adj R-Squared" of 0.9848 . The other terms in the model are not- significant.

Table 9 shows the reduced model for TWR after eliminating the non-significant terms by a backward elimination process. The outcomes indicate that the model is valid as the value of R-Squared and adjusted R-Squared are $98.77 \%$ and $98.58 \%$ respectively with no significant lack of fit. From Fig. 4(a-e), results indicated that current, pulse off-time, tool material and powder particles have the significant effect on TWR, while pulse on-time has the negligible effect. TWR increases, with the increase of current while decreases with the increase of pulse off-time and pulse on-time have the negligible effect as indicated in Fig. 4(a, c and b). This result is in good agreement as reported by Çaydaş and Hasçalik (2008). TWR also increases while using graphite as a tool electrode. From the Fig. 4(e) it is clear that among the three powder particles, tungsten carbide has the significant effect on the TWR. The Fig. 5(a) shows the normal probability plots of the residual for TWR, which indicate that all the residuals lie on the straight line mean errors are normally allocated. Likewise, each value is compared with expected values and noticed that regression model well suited with the observed value as presented in Fig. 5(b). It can be noticed that $3 \mathrm{D}$ surface plots and contour plot favor the results for TWR and can be visualized in Fig. 5(c, d, e, and f) and Fig. 4(f). After the removal of non-significant terms the final equation for TWR is given below:

The equation for TWR in coded form:

$$
\begin{aligned}
\text { Tool wear rate }(\mathrm{TWR})= & +0.086+0.11 \times \mathrm{A} \\
& +0.023 \times \mathrm{B}+0.79 \\
& \times \mathrm{D}+0.045 \times \mathrm{E}+0.84 \\
& \times \mathrm{D}^{2}+0.099 \times \mathrm{B} \times \mathrm{D}
\end{aligned}
$$

Equation for TWR in actual form:

$$
\begin{aligned}
\text { Tool wear rate }(\text { TWR })= & +0.085+0.108 \times \text { Current } \\
& +0.023 \times \text { Pulse on-time }(\text { Ton }) \\
& +0.789 \times \text { Tool }+0.045 \\
& \times \text { Powder }+0.836 \times \text { Tool }^{2} \\
& +0.099 \times \text { Pulse on-time }(\text { Ton }) \\
& \times \text { Tool }
\end{aligned}
$$


Table 8 Analysis of variance for TWR (before elimination)

\begin{tabular}{|c|c|c|c|c|c|c|}
\hline Source & Sum of squares & DF & Mean squares & F - value & Prob $>F$ & \\
\hline Model & 17.61 & 20 & 0.88 & 146.3 & $<0.0001$ & Significant \\
\hline A & 0.19 & 1 & 0.19 & 31.04 & $<0.0001$ & \\
\hline B & $8.60 \times 10^{-03}$ & 1 & $8.60 \times 10^{-03}$ & 1.43 & 0.2431 & \\
\hline C & $7.97 \times 10^{-03}$ & 1 & $7.97 \times 10^{-03}$ & 1.32 & 0.2609 & \\
\hline D & 9.98 & 1 & 9.98 & 1658.23 & $<0.0001$ & \\
\hline E & 0.033 & 1 & 0.033 & 5.44 & 0.028 & \\
\hline$A^{2}$ & $1.30 \times 10^{-03}$ & 1 & $1.30 \times 10^{-03}$ & 0.22 & 0.646 & \\
\hline$B^{2}$ & $4.03 \times 10^{-04}$ & 1 & $4.03 \times 10^{-04}$ & 0.067 & 0.798 & \\
\hline$C^{2}$ & $1.82 \times 10^{-03}$ & 1 & $1.82 \times 10^{-03}$ & 0.3 & 0.5868 & \\
\hline$D^{2}$ & 6.06 & 1 & 6.06 & 1007.42 & $<0.0001$ & \\
\hline$E^{2}$ & $5.41 \times 10^{-04}$ & 1 & $5.41 \times 10^{-04}$ & 0.09 & 0.7668 & \\
\hline$A B$ & $2.30 \times 10^{-03}$ & 1 & $2.30 \times 10^{-03}$ & 0.38 & 0.5417 & \\
\hline$A C$ & 0.013 & 1 & 0.013 & 2.1 & 0.1595 & \\
\hline$A D$ & 0.01 & 1 & 0.01 & 1.66 & 0.2092 & \\
\hline $\mathrm{AE}$ & $4.36 \times 10^{-03}$ & 1 & $4.36 \times 10^{-03}$ & 0.72 & 0.403 & \\
\hline$B C$ & $4.16 \times 10^{-03}$ & 1 & $4.16 \times 10^{-03}$ & 0.69 & 0.4136 & \\
\hline $\mathrm{BD}$ & 0.04 & 1 & 0.04 & 6.58 & 0.0167 & \\
\hline $\mathrm{BE}$ & $1.23 \times 10^{-03}$ & 1 & $1.23 \times 10^{-03}$ & 0.2 & 0.6558 & \\
\hline$C D$ & 0.013 & 1 & 0.013 & 2.12 & 0.1577 & \\
\hline CE & $8.12 \times 10^{-04}$ & 1 & $8.12 \times 10^{-04}$ & 0.13 & 0.7164 & \\
\hline DE & $6.97 \times 10^{-03}$ & 1 & $6.97 \times 10^{-03}$ & 1.16 & 0.2921 & \\
\hline Residual & 0.15 & 25 & $6.02 \times 10^{-03}$ & & & \\
\hline Lack of Fit & 0.14 & 20 & $7.11 \times 10^{-03}$ & 4.26 & 0.0574 & Not significant \\
\hline Pure Error & $8.34 \times 10^{-03}$ & 5 & $1.67 \times 10^{-03}$ & & & \\
\hline Cor. Total & 17.76 & 45 & & & & \\
\hline \multicolumn{5}{|l|}{ Std. Dev. $=0.078$} & \multicolumn{2}{|c|}{ R-Squared $=0.9915$} \\
\hline \multicolumn{5}{|l|}{ Mean $=0.38$} & \multicolumn{2}{|c|}{ Adj R-Squared $=0.9848$} \\
\hline \multicolumn{5}{|l|}{ C.V. $=20.6$} & \multicolumn{2}{|c|}{ Pred R-Squared $=0.9673$} \\
\hline \multicolumn{5}{|l|}{ PRESS $=0.58$} & \multicolumn{2}{|c|}{ Adeq Precision = 36.969} \\
\hline
\end{tabular}

\section{Microstructure analysis}

Figure $6(\mathrm{a}, \mathrm{d}$ and $\mathrm{g})$ show the SEM micrographs of machined surface, machining condition at $\mathrm{I}_{\mathrm{p}}=4 \mathrm{~A}, \mathrm{~T}_{\mathrm{on}}=60 \mu \mathrm{s}$, $\mathrm{T}_{\text {off }}=45 \mu \mathrm{s}, \mathrm{Cu}-\mathrm{Cr}$ electrode in Tungsten- carbide powdermixed dielectric. Profound craters, cracks and micro cracks can be seen from the machined surfaces. The formation of micro cracks is due to the variation of contraction stresses, generation of higher discharge energy resulting in frequent cracking (Lee et al. 1988). The debris particles are also noticed on the machined surface. The presence of the debris particles on the machined surface is due to a combination of powder particle of work material, tool material, and dielectric fluid (Kumar et al. 2015a, 2015b).

Figure $6(\mathrm{~b}, \mathrm{e}$, and $\mathrm{h}$ ) show the SEM micrographs of machined surface, machining condition at $I_{p}=8$ A,
$\mathrm{T}_{\text {on }}=90 \mu \mathrm{s}, \mathrm{T}_{\text {off }}=45 \mu \mathrm{s}$, graphite electrode in cobalt powder-mixed dielectric. It can be noted that in an increase in the discharge current, surface irregularities also increase resulting into deeper and larger craters. This is imputable to the fact that as the electric current increases with pulse on-time, machined material will melt with the most amount of high temperature transfer to the machined surface (Kumar et al. 2013). The longer pulse on-time and current results more thermal energy that vaporizes and melt the workpiece. This results in big craters left on the surface of the workpiece material (Mohnty et al. 2013; Kumar et al. 2015a, 2015b). With the growth in current high discharge, energy is transmitted to the machining zone, so that melting and evaporation take 
Table 9 Analysis of variance for TWR (after backward elimination)

\begin{tabular}{llllll}
\hline Source & Sum of Squares & DF & Mean Square & F - Value & Prob. $>$ F \\
\hline Model & 17.54 & 6 & 2.92 & 521.21 & $<0.0001$ \\
A & 0.19 & 1 & 0.19 & 33.31 & $<0.0001$ \\
B & $8.60 \times 10^{-03}$ & 1 & $8.60 \times 10^{-03}$ & 1.53 & 0.223 \\
D & 9.98 & 1 & 9.98 & 1779.24 & $<0.0001$ \\
E & 0.033 & 1 & 0.033 & 5.84 & 0.0204 \\
D $^{2}$ & 7.29 & 1 & 7.29 & 1300.3 & $<0.0001$ \\
BD & 0.04 & 1 & 0.04 & 7.06 & 0.0114 \\
Residual & 0.22 & 39 & $5.61 \times 10^{-03}$ & & 0.0734 \\
Lack of Fit & 0.21 & 34 & $6.19 \times 10^{-03}$ & 3.71 & Not significant \\
Pure Error & $8.34 \times 10^{-03}$ & 5 & $1.67 \times 10^{-03}$ & & R-Squared $=0.9877$ \\
Cor. Total & 17.76 & 45 & & & Adj R-Squared $=0.9858$ \\
Std. Dev. $=0.075$ & & & & Pred R-Squared $=0.983$ \\
Mean $=0.38$ & & & & & Adeq Precision $=65.095$ \\
C.V. $=19.89$ & & & & & \\
PRESS $=0.3$ & & & & & \\
\hline
\end{tabular}
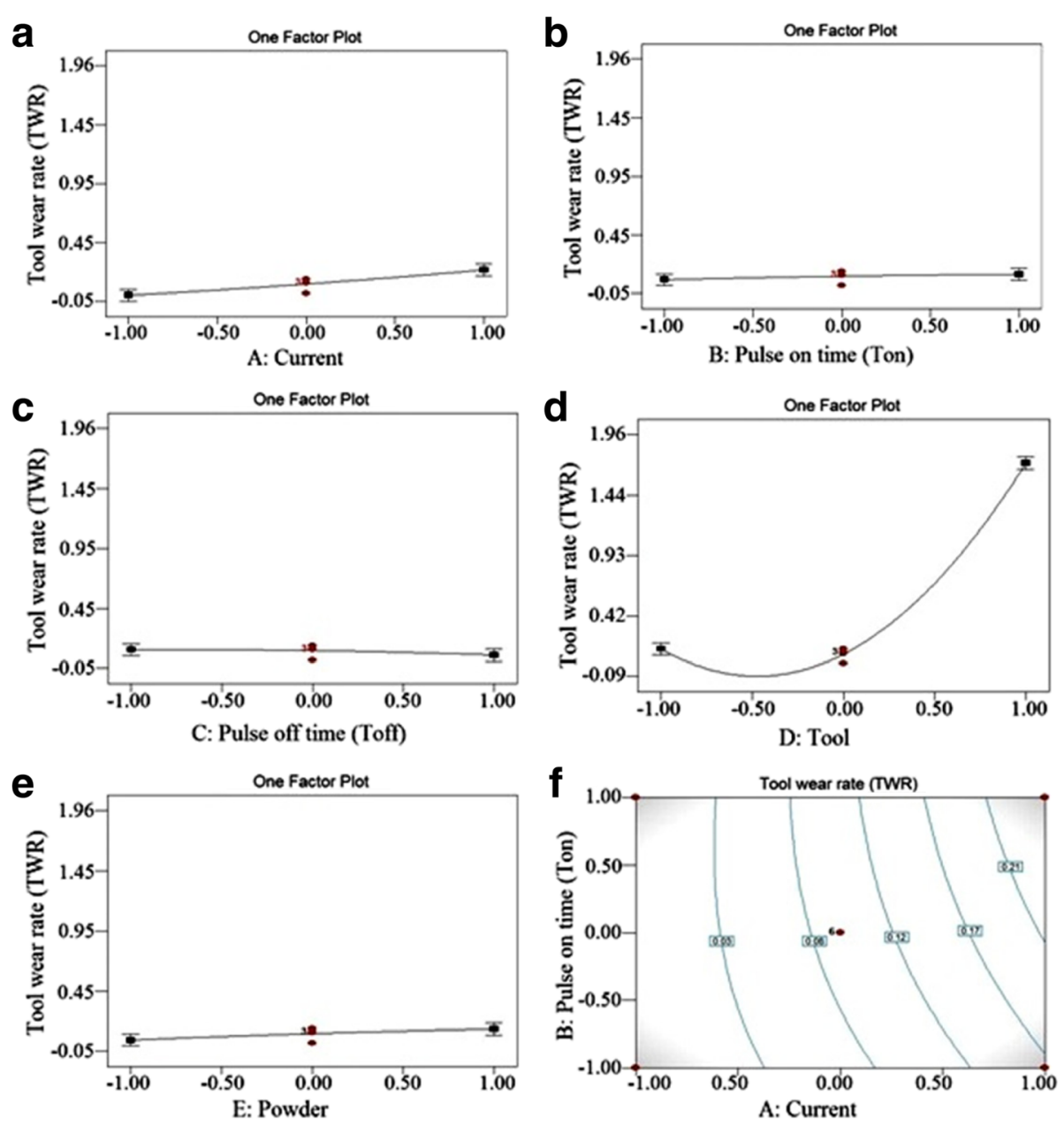

Fig. 4 a, b, c, $\mathbf{d}$ and e One factor plot for TWR; (f) Contour plot for TWR 


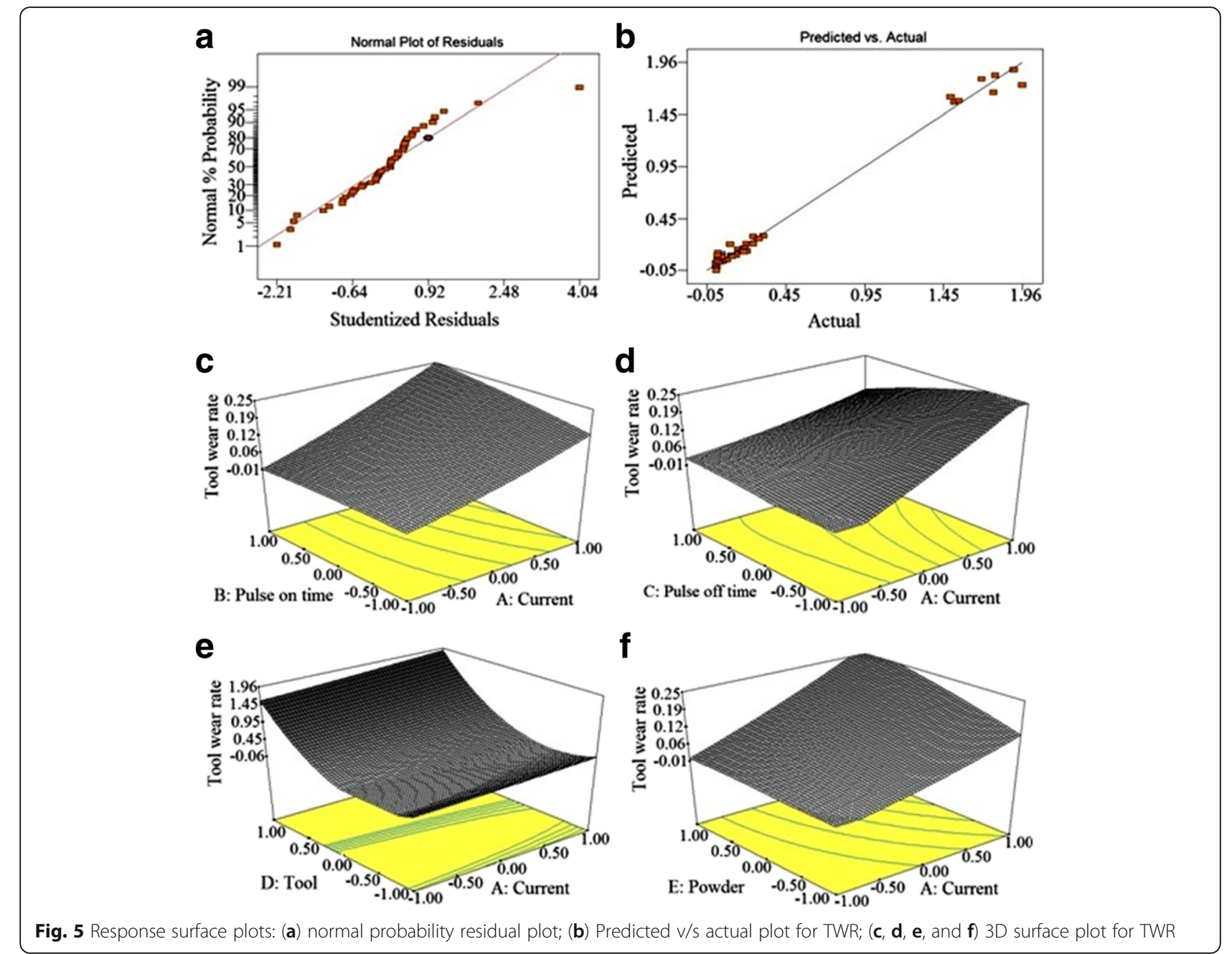

place, resulting in the establishment of a small crater along the surface (Hascalik and Caydas 2007; Kolli and Kumar 2015). Further, due to high discharge energy, the impulsive force also increases, which leads to the formation of deeper and larger crater size which causes rough finish. SEM micrographs of machined surface, machining condition at $\mathrm{I}_{\mathrm{p}}=8 \mathrm{~A}, \mathrm{~T}_{\mathrm{on}}=$ $90 \mu \mathrm{s}, \mathrm{T}_{\text {off }}=60 \mu \mathrm{s}$ graphite electrode in boron carbide powder mixed dielectric are shown in Fig. 6(c, $\mathrm{f}$ and me). It can be seen that at the same discharge current the pulse on-time increases resulting in the formation of sub-surface cracks, deep craters. The magnification scale of Fig. $6(\mathrm{~g}, \mathrm{~h}$ and i) is taken as 2000 times, so that craters, micro cracks and subsurface crack can be well understood.

\section{EDS and XRD analysis}

Energy Dispersive Spectrometer (EDS) shows the presence of foreign particles on the machined surface other than the base material. EDS analyses have been conducted on the selected machined samples for measuring the transferred alloying elements from tool material and powder mixed dielectric. Before PMEDM machining, the weight percentage of elements are $\mathrm{C}=13.55, \mathrm{O}=3.43$, $\mathrm{Al}=0.52, \mathrm{Si}=0.57, \mathrm{Cu}=0.34, \mathrm{Cr}=16.27, \mathrm{Fe}=37.14$ and $\mathrm{Ni}=27.89$ as shown in Fig. 7(a). With PMEDM (experiment no. 44), the weight percentage of an element changes to $\mathrm{C}=13.55$ to $20.31, \mathrm{O}=3.43$ to $2.14, \mathrm{Al}=0.52$ to $0.74, \mathrm{Si}=0.67$ to $0.74, \mathrm{Cr}=16.27$ to $15.44, \mathrm{Fe}=37.14$ to 35.99 and $\mathrm{Ni}=27.89$ to 24.4 as shown in Fig. 7(b). The weight percentage of carbon is increased from 13.55 to 20.31 by using graphite electrode due to deposition of the carbon content from tool electrode to machined surface. Oxide formation can also be observed on the machined surface. Due to the presence of oxygen, oxidation takes place resulting in the degradation of EDM fluid (Lee et al. 1988). Further, in addition to carbon element, other elements, including 


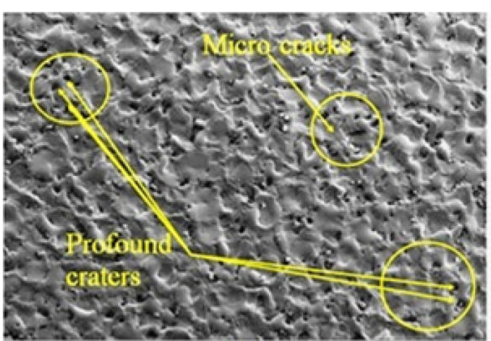

a

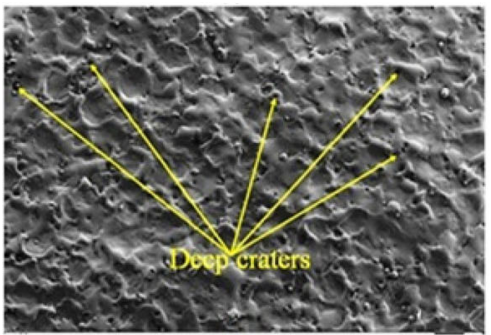

b

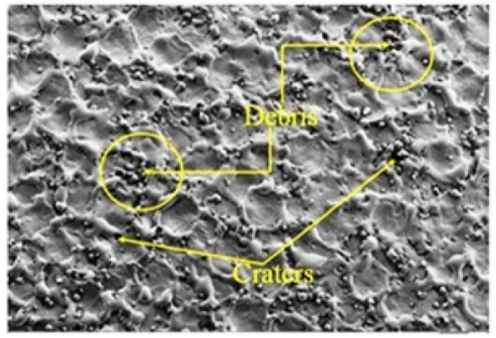

C

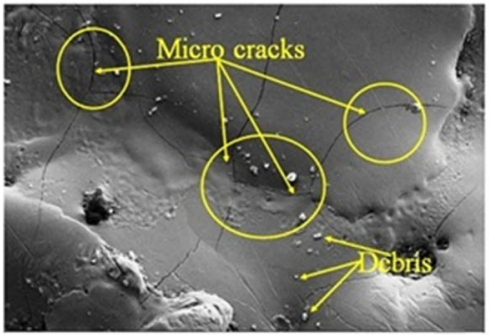

g

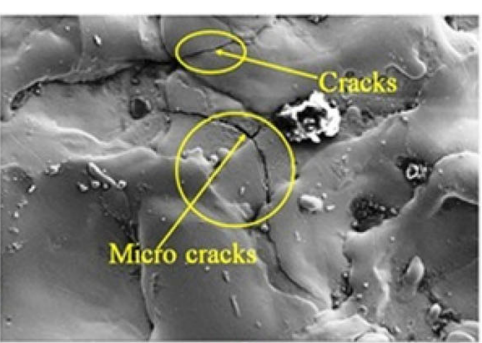

d

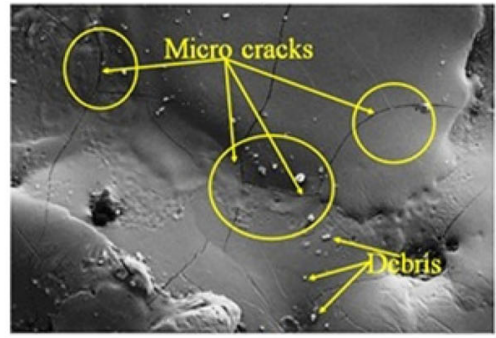

e

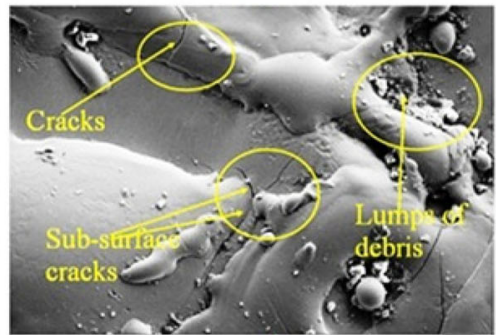

f

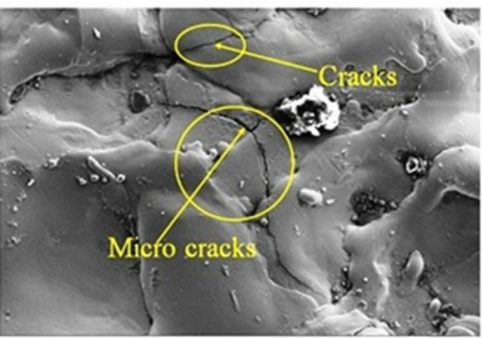

h

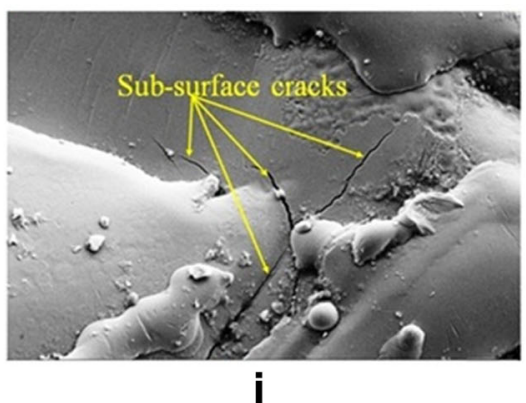

Fig. 6 SEM micrographs $(\times 100, \times 1000$, and $\times 2000)$ of Inconel-800 after PMEDM. a, d and $\mathbf{g}$ Experiment No. 46, at $I_{p}=4$ A, $T_{\text {on }}=60 \mu \mathrm{s}, T_{\text {off }}=45 \mu \mathrm{s}$, $\mathrm{Cu}-\mathrm{Cr}$ electrode in tungsten- carbide powder-mixed dielectric. $\mathbf{b}$, e and $\mathbf{h}$ Experiment No. 44 , at $\mathrm{I}_{\mathrm{p}}=8 \mathrm{~A}, \mathrm{~T}_{\mathrm{on}}=90 \mu \mathrm{s}, \mathrm{T}_{\text {off }}=45 \mu \mathrm{s}$, graphite electrode in cobalt powder-mixed dielectric. $\mathbf{c}, \mathbf{f}$ and $\mathbf{i}$ Experiment No. 03, at $I_{p}=8 \mathrm{~A}, T_{\text {on }}=90 \mu \mathrm{s}, T_{\text {off }}=60 \mu \mathrm{s}$ graphite electrode in boron carbide powder mixed dielectric. $\mathbf{g}$ Experiment No. 46, at $I_{p}=4 \mathrm{~A}, T_{\text {on }}=90 \mu \mathrm{s}, T_{\text {off }}=45 \mu \mathrm{s}$, Cu-Cr electrode in tungsten- carbide powder-mixed dielectric. $\mathbf{h}$ Experiment No. 44 , at $I_{p}=8 \mathrm{~A}, T_{\text {on }}=60 \mu \mathrm{s}, T_{\text {off }}=45 \mu \mathrm{s}$, graphite electrode in cobalt powder-mixed dielectric. $\mathbf{i}$ Experiment No. 03 , at $I_{p}=8 \mathrm{~A}, T_{\text {on }}=90 \mu \mathrm{s}, T_{\text {off }}=60 \mu \mathrm{s}$ graphite electrode in boron carbide powder mixed dielectric 


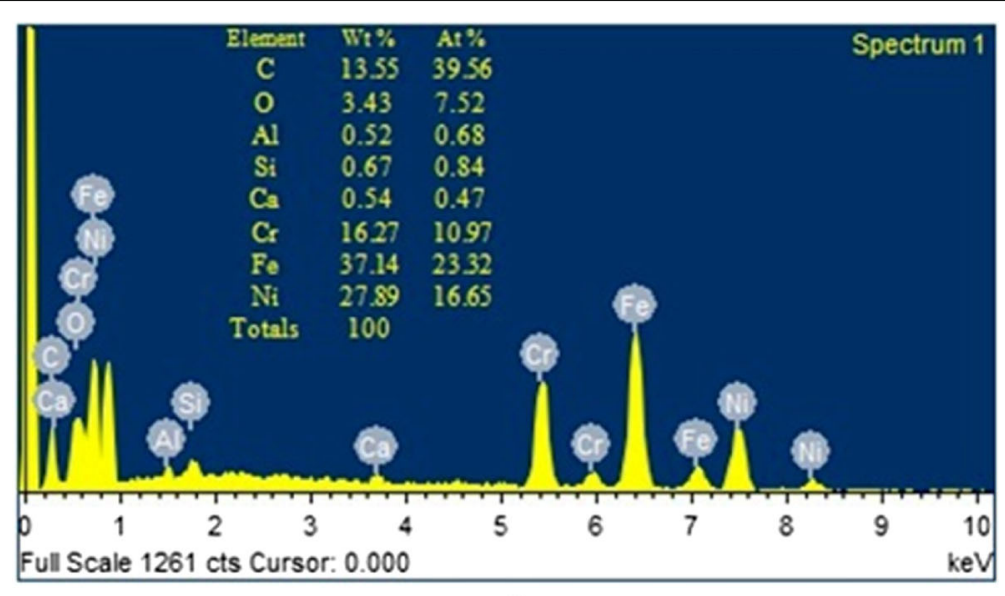

a

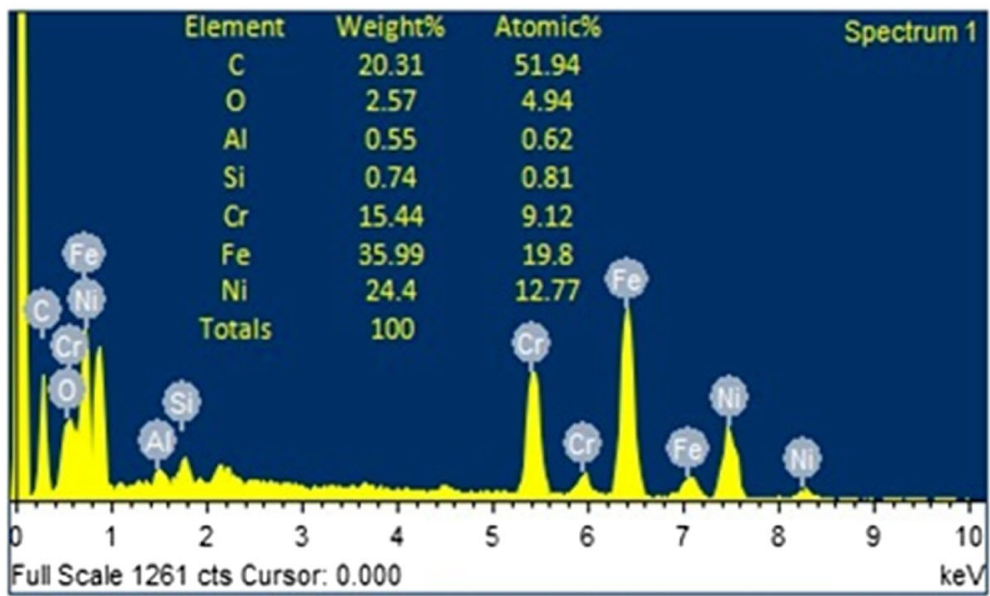

b

Fig. 7 a EDS Analysis of Inconel-800, before PMEDM. b EDS Analysis of Inconel-800, with PMEDM. Experiment No. 44 , at $I_{p}=8 \mathrm{~A}, T_{\text {on }}=90 \mu \mathrm{s}$, $\mathrm{T}_{\text {off }}=45 \mu \mathrm{s}$, graphite electrode in cobalt powder-mixed dielectric

nickel, aluminum, silicon, chromium, iron, and oxygen have been exerted on the surface of workpiece. High peaks of nickel and iron were also observed on the EDS spectrum.

$\mathrm{X}$ - ray diffraction (XRD) analysis also conducted on the selected machined surface for predicting the chemical compounds precisely. XRD technique confirms the transfer of several elements from tool material, dielectric fluid to the machined surface. When the machine is energized, the machined surface comes into contact with the X-rays. XRD analysis was performed using a $\mathrm{KFL} \mathrm{Cu}-2 \mathrm{k}$ source over the $2 \theta$ range from $5^{\circ}$ to $120^{\circ}$, at a temperature of $25^{\circ} \mathrm{C}$ with a scan time 21 minutes for the $15 \mathrm{~mm}$ specimen length. Figure 8(a) and (b) shows the XRD pattern, before and after machining the workpiece samples. Before machining, nickel and chromium compounds were observed at the different $2 \theta$ positions (43.912, 51.031, 74.872, and 91.314). D-value, the intensity at $2 \theta$ positions are 2.06020, 1.78825, 1.07709 and 1.26720. After machining, carbon particles transferred to the machined surface and forms different compounds. Compounds like $\mathrm{Ni}(\mathrm{CO})_{4}, \mathrm{NiO}, \mathrm{Cr}$ (III) $\mathrm{O}_{3}, \mathrm{Cr}$ (III) ${ }_{2} \mathrm{O}_{3}$ have been found on the machined surface at different $2 \theta$ positions with diverse $\mathrm{d}$-value intensities.

\section{Optimization of multi-responses by desirability approach}

One of the valuable methods for optimizing the several responses has to utilize the simultaneous optimization technique developed by Derringer and Suich (1980) which contains the concept of desirability functions. The thought behind the desirability concept is to transform several responses into a individual reply by way of mathematical transformations. The desirability function includes the transfer of each response $\mathrm{Yi}$ in specific desirability function di with variation over the range $0 \leq$ $\mathrm{di} \leq 1$. When the response $\mathrm{Yi}$ is the goal, then $(\mathrm{di}=1)$. 

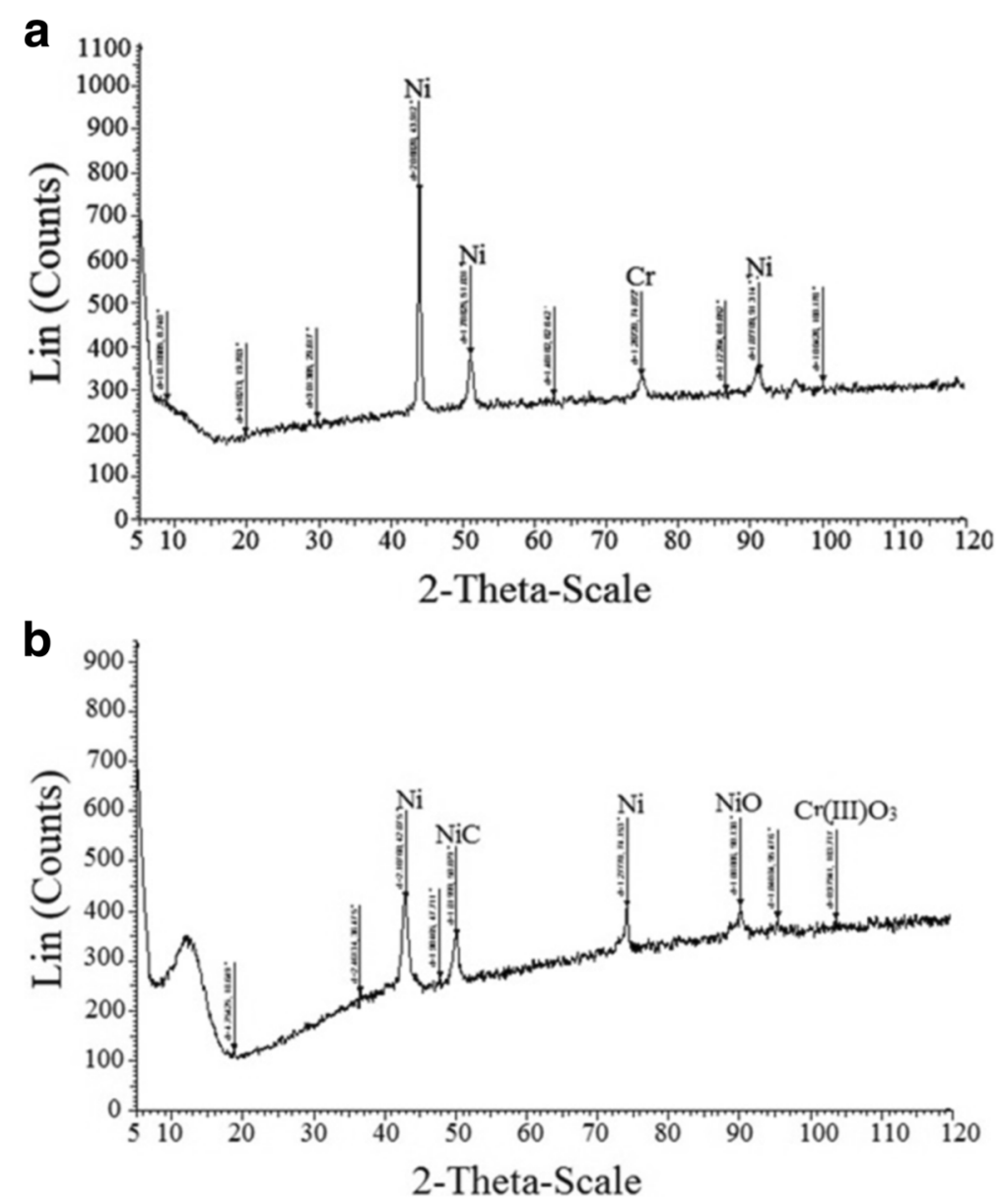

Fig. 8 a XRD analysis of Inconel-800, before machining. $\mathbf{b}$ XRD analysis of Inconel-800, after machining

The response is outside a suitable region when $\mathrm{di}=0$. The simultaneous objective function is a geometric mean of all transformed responses.

$$
\begin{aligned}
& D=\left(d_{1} \times d_{2} \times d_{3} \times \ldots \ldots \ldots d_{n}\right)^{1 / n} \\
& \text { i.e. } D=\left(\sum_{j=1}^{n} d j\right)^{1 / n}
\end{aligned}
$$

Where $\mathrm{n}=$ number of responses and in the present case $\mathrm{n}=2$.
Importance (L) can be given in response parameters. Importance satisfies $0<\mathrm{L}_{\mathrm{i}}<1$ and $\mathrm{L}_{1}+\mathrm{L}_{2}+\mathrm{L}_{3} \ldots \ldots \ldots \mathrm{L}_{\mathrm{n}}$ $=1$.

$$
\mathrm{D}=\left(\mathrm{d}_{1}{ }^{\mathrm{L} 1} \times \mathrm{d}_{2}{ }^{\mathrm{L} 2} \times \mathrm{d}_{3}{ }^{\mathrm{L} 3} \times \ldots \ldots \ldots \mathrm{d}_{\mathrm{n}}{ }^{\mathrm{Ln}}\right)^{1 / \mathrm{n}}
$$

The parameters must be deputed a "Goal" from the options "none," "upper limit," "lower limit," "target,"

\begin{tabular}{|c|c|c|c|c|c|c|}
\hline Name & Goal & Lower Limit & Upper Limit & Lower Weight & Upper Weight & Importance \\
\hline Current & is in range & -1 & 1 & 1 & 1 & 3 \\
\hline Pulse on time (Ton) & is in range & -1 & 1 & 1 & 1 & 3 \\
\hline Pulse off time(Toff) & is in range & -1 & 1 & 1 & 1 & 3 \\
\hline Tool & is in range & -1 & 1 & 1 & 1 & 3 \\
\hline Powder & is in range & -1 & 1 & 1 & 1 & 3 \\
\hline Material removal rate(MRR) & maximize & 4.033 & 35.788 & 1 & 1 & 3 \\
\hline Tool wear rate (TWR) & minimize & 0.002 & 1.957 & 1 & 1 & 3 \\
\hline
\end{tabular}
or "in range." Table 10 demonstrates the constraints

Table 10 Constraints of input parameters 
of input parameters along with the goal and importance assigned to every parameter. Table 11 shows the value of 25 optimal solutions of combinations of input parameters with larger desirability (from 1 to .75). Optimized bar histograms, contour plot, 3D surface plot and ramp plot for the overall desirability of MRR and TWR have been demonstrated in Fig. 9(a), (b), (c) and (d). Optimal combinations of input parameters are current $1 \mathrm{amp}$, pulse on-time $0.98 \mu \mathrm{s}$, pulse off-time $0.03 \mu \mathrm{s}$, tool material 0.31 and powder particles 0.64 .

\section{Confirmations/ validation experiments}

Since the equations for response parameters have been derived from quadratic regression fits, therefore validation test should be performed for verification of the legitimacy. The independent variable values selected for the validation test must be within the limits for which the rules have been derived (Kansal et al. 2005). Three validation tests have been taken out for the MRR \& TWR. The information from the validation trials and their comparisons with the predicted designed for material removal rate and tool wear rate are presented in Table 12. The error in both the cases, i.e. Experimental and predicted values for MRR and TWR are within $\pm 9.8 \%$ and $\pm 8.5 \%$, respectively, which confirms the outstanding reproducibility of the observational outcomes.

\section{Conclusion and future scope}

In the present study, the quadratic models for Material Removal Rare (MRR) and Tool Wear Rate (TWR) have been developed for inter-relating the machining parameters: current, pulse on-time, pulse off-time, tool material and powder particles in the PMEDM process for Inconel-800. The box-Behnken method of RSM has been considered for the design

Table 11 Optimal solutions for MRR and TWR

\begin{tabular}{|c|c|c|c|c|c|c|c|c|c|}
\hline S.No & Current & $\begin{array}{l}\text { Pulse on- time } \\
\text { (Ton) }\end{array}$ & $\begin{array}{l}\text { Pulse off-time } \\
\text { (Toff) }\end{array}$ & Tool & Powder & $\begin{array}{l}\text { Material removal rate } \\
\text { (MRR) }\end{array}$ & $\begin{array}{l}\text { Tool wear rate } \\
\text { (TWR) }\end{array}$ & Desirability & \\
\hline 1 & 1 & 0.98 & 0.03 & 0.31 & 0.64 & 35.92 & 0.009 & 1 & Selected \\
\hline 2 & 0.99 & 0.98 & 0.13 & 0.29 & 0.81 & 36.18 & 0.009 & 1 & \\
\hline 3 & 1 & 0.99 & 0.38 & 0.65 & 1 & 36.05 & 0.008 & 1 & \\
\hline 4 & 1 & 0.89 & 0.23 & 0.76 & 0.87 & 35.89 & 0.003 & 1 & \\
\hline 5 & 0.99 & 0.98 & 0.15 & 0.21 & 0.78 & 35.84 & 0.0007 & 1 & \\
\hline 6 & 0.99 & 0.89 & 0.81 & 0.48 & 1 & 36.07 & 0.0016 & 1 & \\
\hline 7 & 0.97 & 1 & 0.23 & 0.58 & 0.94 & 36.34 & 0.0595 & 1 & \\
\hline 8 & 0.95 & 1 & 0.41 & 0.57 & 0.92 & 35.9 & 0.0396 & 1 & \\
\hline 9 & 0.98 & 0.9 & 0.55 & 0.52 & 0.96 & 35.97 & 0.0231 & 1 & \\
\hline 10 & 0.98 & 0.99 & 0.3 & 0.57 & 0.96 & 35.89 & 0.0005 & 1 & \\
\hline 11 & 1 & 1 & 0.05 & 0.56 & 0.29 & 35.69 & 0.0019 & 0.99 & \\
\hline 12 & 1 & 1 & 0 & 0.43 & 0.02 & 35.66 & 0.0019 & 0.99 & \\
\hline 13 & 1 & 1 & 0.84 & 0.53 & 0.98 & 35.64 & 0.2067 & 0.99 & \\
\hline 14 & 1 & 1 & 0.8 & 1 & 1 & 35.63 & 0.0459 & 0.99 & \\
\hline 15 & 1 & 1 & 0.87 & 0.96 & 1 & 35.53 & 0.085 & 0.99 & \\
\hline 16 & 0.93 & 1 & 0.03 & 0.56 & 1 & 35.78 & 0.0373 & 0.99 & \\
\hline 17 & 1 & 1 & 0.84 & 0.65 & 1 & 35.06 & 0.0905 & 0.98 & \\
\hline 18 & 1 & 1 & 0.89 & 0.24 & 0.7 & 34.3 & 0.0018 & 0.97 & \\
\hline 19 & 0.89 & 1 & 0.4 & 0.54 & 1 & 35.78 & 0.0946 & 0.97 & \\
\hline 20 & 1 & 1 & 1 & 0.58 & 0.78 & 34.25 & 0.1283 & 0.97 & \\
\hline 21 & 0.85 & 0.48 & 1 & 0.3 & 1 & 31.17 & 0.0205 & 0.92 & \\
\hline 22 & 1 & 0.17 & 1 & 0.06 & 0.97 & 30.72 & 0.0019 & 0.91 & \\
\hline 23 & 1 & -0.15 & 1 & 0.47 & 1 & 27.16 & 0.15 & 0.82 & \\
\hline 24 & 1 & -0.3 & 1 & 0.23 & 1 & 25.2 & 0.0019 & 0.81 & \\
\hline 25 & 0.53 & -0.31 & 0.76 & 0.08 & 1 & 22.34 & 0.0366 & 0.75 & \\
\hline
\end{tabular}




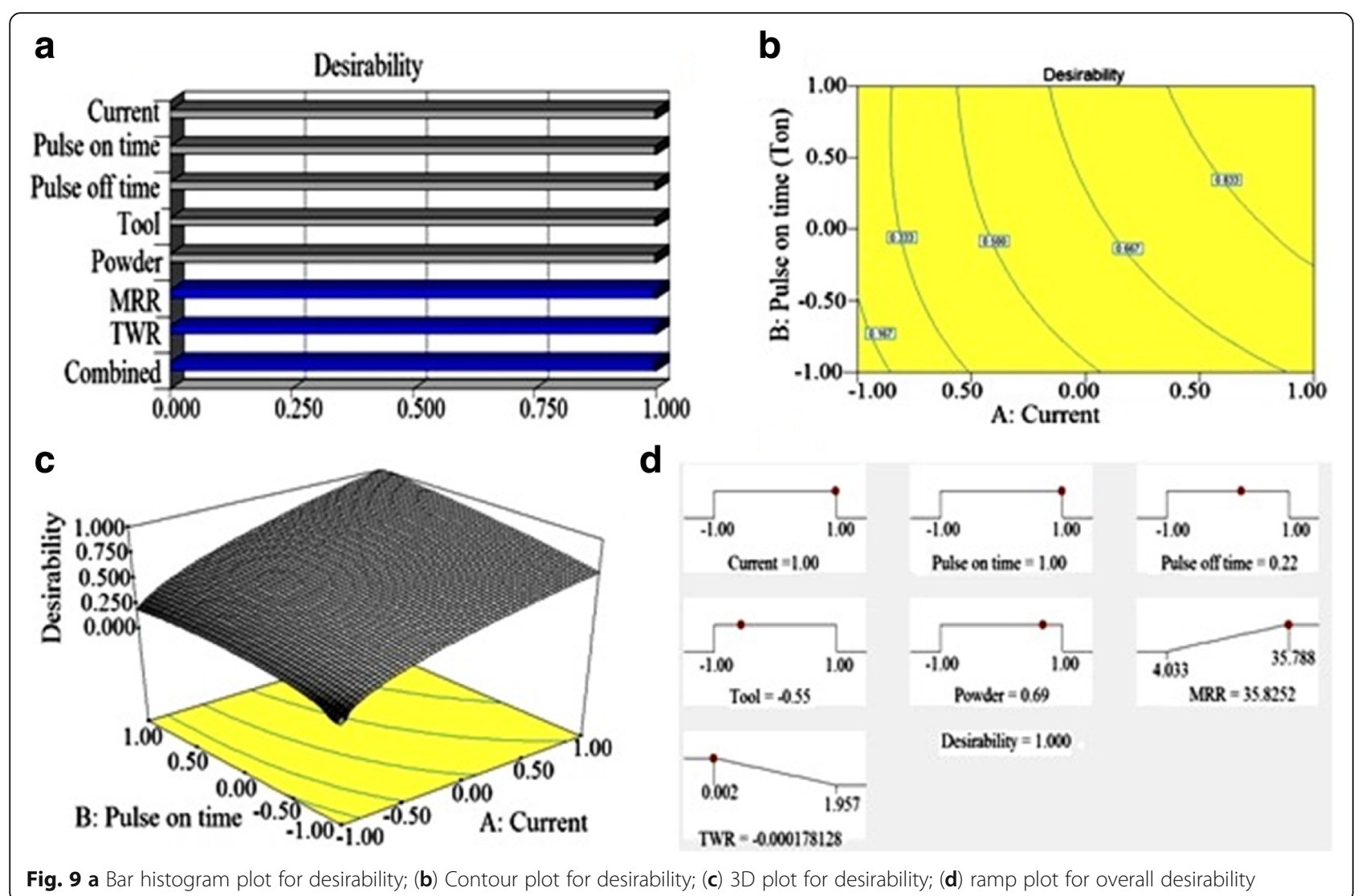

the experiments. From the analysis, current, pulse on-time and tool material have found to be the most decisive factors for MRR, while current, pulse ontime, tool material and powder particles for TWR. Pulse off-time has a trifling effect on both the responses while powder particles on MRR. The MRR varied from 4.033 to $35.788 \mathrm{~mm}^{3} / \mathrm{min}$ and TWR from 0.002 to $1.957 \mathrm{~mm}^{3} / \mathrm{min}$. The error between experimental and expected values for material removal rate and tool wear rate within $\pm 9.8 \%$ and \pm $8.5 \%$, respectively. This confirms an outstanding reproducibility of the experimental results. From multiple response optimizations, the optimal combination of parameters are current $1 \mathrm{amp}$, pulse ontime $0.98 \mu \mathrm{s}$, pulse off-time $0.03 \mu \mathrm{s}$, tool material
0.31 and the powder (suspended particles) 0.64. It is clear from SEM micrographs that the current, pulse on-time and tool material affects the integrity of machined specimen resulting in the formation of debris, deep craters, micro cracks and pock marks. Residuals of carbon and copper have also been identified on the machined surface during the EDS and XRD analysis.

In the present work, three micro powder particles, i.e. tungsten carbide, cobalt and boron carbide along with three electrodes i.e. copper, copper-chromium, and graphite have been considered for the optimization of MRR and TWR. The work can be extended with the combination of other powder particles and electrodes along with more response parameters.

Table 12 Confirmation test and comparison with the results

\begin{tabular}{|c|c|c|c|c|c|c|c|c|c|c|c|}
\hline \multicolumn{6}{|c|}{ Machining Conditions } & \multicolumn{3}{|c|}{$\operatorname{MRR}\left(\mathrm{mm}^{3} / \mathrm{min}\right)$} & \multicolumn{3}{|c|}{ TWR $\left(\mathrm{mm}^{3} / \mathrm{min}\right)$} \\
\hline $\begin{array}{l}\text { S. } \\
\text { No }\end{array}$ & $\begin{array}{l}\text { Current, A } \\
\text { (amp) }\end{array}$ & $\begin{array}{l}\text { Ton, B } \\
(\mu s)\end{array}$ & $\begin{array}{l}\text { Toff, C } \\
(\mu s)\end{array}$ & $\begin{array}{l}\text { Tool } \\
\text { material }\end{array}$ & Powder & $\begin{array}{l}\text { Exp. } \\
\text { value }\end{array}$ & $\begin{array}{l}\text { Predicted } \\
\text { value }\end{array}$ & $\begin{array}{l}\text { Error } \\
(\%)\end{array}$ & $\begin{array}{l}\text { Exp. } \\
\text { value }\end{array}$ & $\begin{array}{l}\text { Predicted } \\
\text { value }\end{array}$ & $\begin{array}{l}\text { Error } \\
(\%)\end{array}$ \\
\hline 1 & 4 & 90 & 60 & $\mathrm{Cu}-\mathrm{Cr}$ & Co & 4.35 & 3.93 & 9.88 & 0.017 & 0.016 & 5.88 \\
\hline 2 & 8 & 60 & 45 & $\mathrm{Cu}$ & WC & 13.29 & 14.41 & -8.42 & 0.024 & 0.026 & -8.33 \\
\hline 3 & 12 & 120 & 45 & $\mathrm{Gr}$ & Co & 35.79 & 35.34 & 1.25 & 0.28 & 0.25 & 8.57 \\
\hline
\end{tabular}




\section{Acknowledgement}

The authors acknowledge the Assistant Director, Central Institute of Hand Tools, Jalandhar, Punjab, INDIA, for providing the EDM set-up and other services during the research work. Also highly thankful to Dr. Sushil Mittal, Assistant Professor, HCTM, Technical Campus, Kaithal, Haryana, INDIA for providing assistance during the research work.

\section{Authors' contributions}

Er. Satish planned and conducted the experiments and compiled all the data under the supervision of Dr. Dhingra in the model designing and the statistical analysis. Dr. Sanjeev takes part in the sequence alignment and drafted the manuscript. All the authors read and approved the final manuscript.

\section{Competing interests}

The authors declare that they have no competing interests.

\section{Publisher's Note}

Springer Nature remains neutral with regard to jurisdictional claims in published maps and institutional affiliations.

\section{Author details}

'Department of Mechanical Engineering, University Institute of Engineering \& Technology, Maharshi Dayanand University, Rohtak 124001, Haryana, India. 2Department of Mechanical Engineering, Chandigarh Engineering College, Landran, Punjab, India.

Received: 30 September 2016 Accepted: 24 March 2017

Published online: 17 April 2017

\section{References}

Abbas NM, Solomon DG, Bahari MF (2007) A review on current research trends in electrical discharge machining (EDM). Int J Mach Tool Manuf 47(7-8):1214-1228

Çaydaş U, Hasçalik A (2008) Modeling and analysis of electrode wear and white layer thickness in die-sinking EDM process through response surface methodology. Int J Adv Manuf Technol 38(11):1148-1156.

Derringer G, Suich R (1980) Simultaneous optimization of several response variables. J Quality Technol 12(4):214-219

Ekmekci B, Erden A (2004) Remarks on surface integrity of electric discharge machined surfaces: A state of art review. Paper presented at 11th International Conference on Machine Design and Production, Antalya, Turkey, pp 411-428

Hascalik A, Caydas U (2007) Electric discharge machining of titanium alloy. Appl Surf Sci 253:9007-9016

Jeswani ML (1981) Effect of the addition of graphite powder to kerosene used as the dielectric fluid in electrical discharge machining. Wear 70(2):133-139

Kansal HK, Singh S, Kumar P (2005) Parametric optimization of powder mixed electrical discharge machining by response surface methodology. J Mater Process Technol 169:427-436

Khazraji A, Amin SA, Ali SM (2016) The effect of SiC powder mixing electrical discharge machining on white layer thickness, heat flux and fatigue life of AISI D2 die steel. Eng Sci Technol An Int J 19:1400-1415

Klocke F, Lung D, Antonoglou G, Thomaidis D (2004) The effects of powder suspended dielectrics on the thermal influenced zone by electro-discharge machining with small discharge energies. J Mater Process Technol 149:191-197

Kolli M, Kumar A (2015) Effect of dielectric fluid with surfactant and graphite powder on Electrical Discharge Machining of titanium alloy using Taguchi method. Eng Sci Technol An Int J 18:524-535

Kumar A, Maheshwari S, Sharma C, Beri N (2009) Performance evaluation of silicon additive in electrical discharge machining of EN 24 steel based on Taguchi method. J Mech Eng 60(5-6):298-304

Kumar A, Maheshwari S, Sharma C, Beri N (2010a) Research developments in Additives Mixed Electrical Discharge Machining (AEDM): a state of art review. Mater Manuf Process 25:1166-1180

Kumar A, Maheshwari S, Sharma C, Beri N (2010b) A study of multi-objective parametric optimization of silicon abrasive mixed electrical discharge machining of tool steel. Mater Manuf Process 25:1041-1047

Kumar A, Maheshwari S, Sharma C, Beri N (2012) Machining efficiency evaluation of cryogenically treated copper electrode in additive mixed EDM. Mater Manuf Process 27:1051-1058

Kumar A, Kumar V, Kumar J (2013) Multi-response optimization of process parameters based on response surface methodology for pure titanium using WEDM process. Int J Adv Manuf Technol 10:4861-9
Kumar S, Singh R, Batish A, Singh TP (2015a) Study the surface characteristics of cryogenically treated tool-electrodes in powder mixed electric discharge machining process. Mater Sci Forum 808:19-33

Kumar S, Batish A, Singh R, Singh TP (2015b) A mathematical model to predict material removal rate during electrical discharge machining of cryogenically treated titanium alloys. J Eng Manuf 229(2):214-228

Kung KY, Horng JT, Chiang KT (2009) Material removal rate and electrode wear ratio study on the powder mixed electrical discharge machining of cobalt-bonded tungsten carbide. Int J Adv Manuf Technol 40:95-104

Lee LC, Lim LC, Narayanan, Venkatesh VC (1988) Quantification of surface damage of tool steels after EDM. Int J Mech Tool Manuf 28(4):359-372

Lin YC, Tsao CC, Hsu CY, Hung SK, Wen DC (2012) Evaluation of the characteristics of the micro electrical discharge machining process using response surface methodology based on the central composite design. Int J Adv Manuf Technol 62:1013-1023

Long BT, Phan NH, Cuong N, Jatti VK (2016) Optimization of PMEDM process parameter for maximizing material removal rate by Taguchi's method. Int J Adv Manuf Technol 87:1929-1939

Mohanty CP, Mahapatra SS, Singh MR (2014) An experimental investigation of machinability of inconel-718 in electrical discharge machining. Procedia Mater Sci 6:605-611

Mohnty CP, Sahu J, Mahapatra SS (2013) Thermal-structural analysis of electrical discharge machining process. Procedia Eng 51:508-513

Montgomery DC, Peak EA, Vining GG (2003) Introduction to Linear Regression Analysis, 3rd edn. Wiley, New York

Muthukumar V, Rajesh N, Venkatasamy R, Sureshbabu A, Senthilkumar N (2014) Mathematical modeling for radial overcut on electrical discharge machining of incoloy 800 by response surface methodology. Pro Mater Sci 6:1674-1682

Natarajan U, Periyanan PR, Yang SH (2011) Multiple-response optimization for micro-end milling process using response surface methodology. Int J Adv Manuf Technol 56:177-185

Prabhu S, Vinayagam BK (2012) Modeling the machining parameters of AISI D2 tool steel material with multi wall carbon nano tube in electrical discharge machining process using response surface methodology. Int J Phy Sci 7(2):297-305

Rajesh R, Anand MD (2012) The optimization of the electro-discharge machining process using response surface methodology and genetic algorithms. Procedia Eng 38:3941-3950

Singh J, Sharma RK (2016) Implementation of Taguchi method with hybrid decision making tools for prediction of surface characteristics for powder-mixed EDM of WC. J Eng Mate Sci 8:455-458

Singh S, Yeh MF (2012) Optimization of abrasive powder mixed EDM of aluminum matrix composites with multiple responses using gray relational analysis. J Mater Eng Perfor 21:481-491

Singh S, Maheshwari S, Dey A (2006a) Electrical Discharge Machining (EDM) of aluminum metal matrix composites using powder-suspended dielectric fluid. J Mech Eng 57(5):271-290

Singh S, Maheshwari S, Pandey PC (2006b) An experimental investigation into Additive Electrical Discharge Machining (AEDM) of Al2O3 particulate reinforced Al-based metal matrix composites. J Mech Eng 57(1):13-33

Sushil M, Vinod K, Harmesh K (2016) Multi-response optimization of process parameters involved in micro-finishing of Al/SiC MMCs by abrasive flow machining process. Proceedings of the IMechE, Part L: J Mater: Des App (First published date: January-13-2016). doi:10.1177/1464420715627292.

Talla G, Sahoo DK, Gangopadhyay S, Biswas CK (2015) Modeling and multi-objective optimization of powder mixed electric discharge machining process of aluminum/alumina metal matrix composite. Eng Sci Technol Int J 18:369-373

Talla G, Gangopadhyay S, Biswas CK (2016) Effect of powder-suspended dielectric on the EDM characteristics of inconel 625. J Mater Eng Perfor 25:704-717

Toshimitsu R, Okada A, Kitada R, Okamoto Y (2016) Improvement in surface characteristics by EDM with chromium powder mixed fluid. Procedia CIRP 42:231-235

Tzeng YF, Lee C (2001) Effects of powder characteristics on electro discharge machining efficiency. Int J Adv Manuf Technol 17(8):586-592

Vikram S, Pradhan SK (2014) Optimization of EDM process parameters: a review. Inter J Emerg Technol Adv Eng 4:345-355

Wu KL, Yan BH, Lee JW, Ding CG (2009) Study on the characteristics of electrical discharge machining using dielectric with surfactant. J Mater Process Technol 209:3783-3789

Zhang JH, Lee TC, Lau WS, Ai X (1997) Spark erosion with ultrasonic frequency. J Mater Process Technol 68(1):83-88 